\title{
Paraneoplastic Rheumatic Disorders
}

\author{
Paraneoplastik Romatizmal Hastalıklar
}

\begin{abstract}
Ömer Faruk ŞENDUR
Department of Physical Medicine and Rehabilitation, Medical Faculty of Adnan Menderes University, Aydin, Turkey
\end{abstract}

Paraneoplastic rheumatic disorders are defined as rheumatic symptoms resulting from an underlying malignant disease, which is not directly related to a tumor or metastasis. The clinical course of the disease is generally in parallel with the underlying malignancy. Such kind of rheumatic symptoms are unresponsive to conventional treatments, while mostly improve with successful treatment of the underlying malignancy. Early diagnosis of malignancies may be possible with suspicion of paraneoplastic rheumatic disorders by physicians in such cases.

Key words: Malignancies; paraneoplastic syndromes; rheumatic diseases.

The term "paraneoplastic syndromes" refers to symptoms caused by a malignancy but which are not directly related to the tumor mass nor its metastasis. These kinds of symptoms are present in approximately $10 \%$ of all cancer cases at the time of diagnosis. Approximately $50 \%$ of cancer patients experience paraneoplastic symptoms at least once during their disease. Although the majority of these are endocrine in nature, hematological, rheumatic, and neurological symptoms are also seen. ${ }^{[1]}$

The concomitant presence of malignancies with rheumatic diseases may appear in various forms: (i) metastasis to musculoskeletal system (ii) nonmetastatic paraneoplastic rheumatic diseases (iii) malignancies secondary to a rheumatic disease (iv) malignancies which developed as complications due to immunosuppressive drugs used for the treatment
Altta yatan malign bir hastalık nedeniyle ortaya çıkan, tümör veya metastaz ile direkt ilişkisi olmayan romatizmal semptomlar paraneoplastik romatizmal hastalıklar olarak tanımlanır. Hastalığın klinik seyri, genellikle altta yatan malignensi ile paralellik gösterir. Bu tip romatizmal semptomlar konvansiyonel tedavilere yanıt vermezken, çoğunlukla altta yatan malignensinin başarılı tedavisi ile düzelir. Bu tip olgularda hekimin paraneoplastik romatizmal hastalıklardan şüphelenmesi malignensinin erken tanı almasını sağlayabilir.

Anahtar sözcükler: Maligniteler; paraneoplastik sendromlar; romatizmal hastalıklar.

of rheumatic diseases $(v)$ rheumatic diseases which developed as complications from malignancy treatments.

This review focuses on paraneoplastic rheumatic disorders (RDs). This involves the non-metastatic distant effects of tumors on the musculoskeletal system. The main distinguishing feature between paraneoplastic RD and tumors associated with RDs is that the rheumatic symptoms in the former are decreased or abolished by excision or radical treatment of the tumor. The majority of paraneoplastic RDs precede the onset of the malignancy by months or even years. Although some types of paraneoplastic RDs are very rarely reported in the literature, we believe that this number should be higher. Unfortunately, a lack of knowledge about this condition causes delays in diagnosis and loss of very precious time.

Received: February 22, 2012 Accepted: February 28, 2012

Correspondence: Ömer Faruk Şendur, M.D. Adnan Menderes Üniversitesi Tıp Fakültesi Fiziksel Tıp ve Rehabilitasyon Anabilim Dalı, 09100 Aydın, Turkey. Tel: +90 256 - 4441256 e-mail: ofsendur@yahoo.com

C2012 Turkish League Against Rheumatism. All rights reserved. 


\section{PATHOGENESIS}

Decreasing paraneoplastic RD symptoms in line with the primary tumor treatment can provide an idea about the pathogenesis. There are three proposed hypotheses: ${ }^{[2]}$

a) Paraneoplastic RD and malignancy are independently triggered by the same initiative factor (bacteria, virus, radiation, etc.)

b) Paraneoplastic RD is caused by toxins produced by the tumor cells, which trigger inflammation.

c) Paraneoplastic RD is mediated by hypersensitivity reaction, which develops against intracellular antigens secreted by apoptotic cancer cells. The presence of autoantibodies against nuclear proteins and doublestranded deoxyribonucleic acid (ds-DNA) in the serum of people with paraneoplastic RD is used as evidence for this suggestion. ${ }^{[3]}$

\section{CLASSIFICATION}

It was first reported in 1916 that a rheumatic disease could herald a malignancy. ${ }^{[4]}$ Many paraneoplastic RDs have been defined since that time (Table 1).

\section{ARTHRITIS \\ Carcinomatous Polyarthritis (Rheumatoid Arthritis-Like)}

Carcinomatous polyarthritis is a seronegative inflammatory arthritis and may be the first sign of an existent malignancy. Although the pathogenesis of synovitis is not clearly known, possible pathogenic factors include immune mechanisms such as hormones, cytokines, peptides, antibodies and cytotoxic lymphocytes. ${ }^{[5]}$

Carcinomatous polyarthritis has been associated with breast, lung, colon, ovarian, gastric, and oropharynx cancer as well as esophageal tumors and lymphoproliferative diseases. ${ }^{[2,6,7]}$ Usually the symptoms appear eight to 12 months before the development of tumor disease. ${ }^{[2]}$ It differs from rheumatoid arthritis (RA) due to the initiation at advanced age, acute onset, predominantly asymmetrical lower extremity involvement, and sparing of wrist and hand joints. Also, unlike RA, the absence of erosions, deformities, rheumatoid factor, rheumatoid nodules, and family history is observed. ${ }^{[8]}$ Furthermore, joint radiographs tend to be normal. If a patient with such symptoms also has disproportional pain, severe weight loss, hepatosplenomegaly, lymphadenomegaly, inadequate response to steroids, or disease-modifying drugs, then further investigation regarding malignancies should be performed. Symptoms in carcinomatous polyarthritis do not respond to conventional anti-rheumatic treatment. A successful cure is obtained by treating the underlying malignancy.

\section{Hypertrophic osteoarthropathy (HOA)}

Hypertrophic osteoarthropathy is mostly associated with lung adenocarcinoma. The prevalance varies between $6 \%$ and $12 \%{ }^{[9,10]}$ It may also occur in patients with lung metastases of other malignancies, pleural mesothelioma, or intrathoracic lymphoma. The symptoms emerge months before the underlying malignancy. ${ }^{[1]]}$ Although the exact etiology is unknown, humoral, vascular, immunologic, and vagal neural reflex mechanisms are implicated in the pathogenesis. ${ }^{[10,12]}$

The classical disease triad for HOA is the combination of oligo or polyarthritis, clubbing in the toes and fingers, and periostitis at the distal ends of long bones. Rapid progression is seen with this disease, which is related to malignancy. Sometimes a burning pain accompanies the clubbing of fingers. Arthritis is mostly seen in the metacarpophalangeal joints, knees, ankles, elbows, wrists, and proximal interphalangeal joints. They are usually symmetrical and painful. However, synovial fluid analysis shows no sign of

Table 1. Classification of paraneoplastic syndromes

Arthritis

Carcinomatous polyarthritis

Hypertrophic osteoarthropathy

Amyloid arthritis

Secondary gout

Vasculitides

Paraneoplastic vasculitis

Raynaud's syndrome and digital gangrene

Erythromelalgia

Skin and muscle diseases

Dermatomyositis and polymyositis

Scleroderma-like syndrome

Erythema nodosum

Lambert-Eaton syndrome

Palmar fasciitis

Panniculitis

Eosinophilic fasciitis

Unclassified syndromes

Reflex sympathetic dystrophy

Lupus-like syndromes

Recurrent polychondritis

Multicentric reticulohistiocytosis

Oncogenic osteomalacia 
inflammation. ${ }^{[1]}$ Deeply localized bone pain is present due to periostitis. The pain is especially prominent at the distal part of the lower extremities and typically increases during movement and decreases when the legs are elevated. These patients may have skin thickening at the forehead and neck as well as gynecomastia. ${ }^{[10]}$

There is no specific laboratory sign. The sedimentation rate is usually high. Alkaline phosphatase levels may be higher in cases with periostitis. Symmetrical periostitis may be observed in direct radiographies of the long bones. Scintigraphic abnormalities may precede the radiographic findings. Although pain is relieved by nonsteroidal antiinflammatory drugs (NSAIDs), a cure is only possible by treating the underlying neoplasm.

\section{Amyloid arthritis}

Amyloid arthritis is generally described in patients with multiple myeloma. The arthritis is characterized by monoclonal light chains (AL amyloid) accumulation at synovium. Typically it involves the shoulders, knees and wrists bilaterally and is relatively painless. Sinovial effusions are non-inflammatory and contain amyloid deposits. ${ }^{[8,13]}$ The diagnosis can be confirmed by bone marrow examination, serum and urine electrophoresis, or a biopsy of the synovium. Carpal tunnel syndrome, subcutaneous amyloid deposition, macroglossia, cardiomyopathy, and nephropathy are other clinical manifestations. The disease responds to the treatment for multiple myeloma and symptomatic treatment of arthritis with NSAIDs.

\section{Secondary gout}

Hyperuricemia and gout are mainly associated with hematological malignancies (leukemia, polycythemia vera, lymphomas, etc.), but they may also develop as a result of the rapid lysis of cells after chemotherapy. The severity of gout changes with the severity of the underlying malignancy, liver involvement, and presence of hypercalcemia. Hyperuricemia can be prevented by adequate hydration and allopurinol treatment before chemotherapy. ${ }^{[3]}$

\section{VASCULITIDES}

\section{Paraneoplastic vasculitides}

Cutaneous leukocytoclastic vasculitis (LV) is the most frequently encountered paraneoplastic vasculitis, ${ }^{[14]}$ with palpable purpura, urticaria, and maculopapular eruptions being observed, Sometimes it is also accompanied by arthritis. Skin lesions may be seen before, at the time of, or after the diagnosis of malignancies. Cutaneous LV may be associated with myeloproliferative and lymphoproliferative diseases along with myelodysplastic syndrome. Lesions are similar to those observed in patients without underlying malignancies. However, older age, the absence of any infection, or the presence of an autoimmune disease, which can explain the vasculitis, chronic relapses, and unresponsiveness to conventional treatments, should suggest an underlying malignancy.

Polyarthritis nodosa is the second most frequent type of paraneoplastic vasculitis. ${ }^{[14]}$ It is mostly associated with hairy cell leukemia. The clinical manifestation consists of fever, cutaneous vasculitis, myalgia, arthritis, acute abdomen due to mesenteric vasculitis, and foot drop due to mononeuritis multiplex.

Although the etiology of paraneoplastic vasculitis is not yet clearly known, suggested mechanisms are: (i) vascular damage caused by cross-reactions between antibodies against tumor cells and the vascular endothelium (ii) vascular inflammation caused by immune complexes involving tumor antigens (iii) direct vascular damage caused by the hairy cells in hairy cell leukemia. Autoantibodies, such as rheumatoid factor, the antineutrophil cytoplasmic antibody, and antinuclear antibodies, are negative in patients with paraneoplastic vasculitis. ${ }^{[15,16]}$

\section{Raynaud's syndrome}

Raynoud's syndrome may occur in association with gastrointestinal, lung, ovarian, and renal carcinoma or with lymphoproliferative diseases. The symptoms are generally asymmetric with digital gangrene. Underlying malignancy should be considered in severe Raynoud cases, especially in individuals 50 years of age or older. Cryoglobulinemia, vasospasm due to immune complexes, hypercoagulopathy, and vasculitis are suggested as possible causes of the pathogenesis. ${ }^{[6,8]}$

\section{Paraneoplastic erythromelalgia}

Erythromelalgia is characterized by burning pain, erythema, and a feeling of heat on the feet or hands without evidence of arterial occlusion. Symptoms are increased by exercise and exposure to heat. About 20\% of secondary erythromelalgia cases occur in patients with myeloproliferative diseases, such as polycythemia rubra vera and essential thrombocythemia. Symptoms may begin months or years before the principal disease. Therefore, blood count tests should be performed regularly in these patients. Daily 325-650 mg aspirin intake is recommended. Erythromelalgia can be treated by the management of the underlying malignancy. ${ }^{[17,18]}$ 


\section{SKIN AND MUSCLE DISEASES}

\section{Dermatomyositis, polymyositis (DM, PM)}

The relationship between malignancies and myositis has not yet been clearly identified. Increased cancer incidence among patients with DM is well known. ${ }^{[19]}$ Additionally, DM and PM can be associated with various malignancies, such as lung, ovarian, breast, and nasopharyngeal carcinoma along with testis tumors, lymphoma, leukemia, and malign melanoma. ${ }^{[20]}$ More severe skin lesions are seen in patients with paraneoplastic DM, and they do not respond to conventional immunosuppressive treatment. ${ }^{[3,19]}$ Cancer associated with myositis is generally described in older people, with the risk being higher in females. ${ }^{[3,21]}$

\section{Scleroderma-like syndrome}

Scleroderma like-skin changes can be observed concomitantly with gastric, breast, and lung tumors as well as with metastatic melanoma and osteoclastic myeloma. ${ }^{[22]}$ POEMS syndrome is defined as osteoclastic myeloma associated with polyneuropathy, endocrinopathy, monoclonal protein and scleroderma-like skin lesions. Antitopoisomerase I antibody levels are higher in oncological patients who have scleroderma-like skin changes. ${ }^{[3]}$ However, the skin lesions do not improve with the treatment of the underlying malignancy. Therefore, this situation is considered to be a kind of metastasis rather than a paraneoplastic event. ${ }^{[23]}$

\section{Paraneoplastic erythema nodosum}

Paraneoplatic erythema nodosum (EN) is a type of panniculitis that is observed idiopathically or secondarily to drugs, infections, and rheumatic diseases. However, if it persists longer than six weeks, malignancy-associated EN should be considered. Paraneoplastic EN occurs most commonly in patients with Hodgkin's lymphoma, non-Hodgkin's lymphoma, and leukemia. Cases of hepatocellular carcinoma have also been reported. The lesions regress after treatment of the underlying malignancy. ${ }^{[24,25]}$

\section{Lambert-Eaton syndrome (LES)}

Lambert-Eaton syndrome occurs most frequently in patients with small-cell carcinoma of the lungs, which affects about $16 \%$ of patients. ${ }^{[26,27]}$ It is characterized by severe fatigue, weakness in the proximal muscles, especially at the lower extremities, and hyporeflexia and is the result of a decreased acetylcholine release at the presynaptic neuromuscular junction and cholinergic autonomic endings. Underlying malignancy may be diagnosed approximately one to two years after the initiation of muscle strength loss. ${ }^{[8]}$ There are no pathophysiological or clinical differences between primary LES and paraneoplastic LES. It is believed that autoantibodies against the cellular membrane of small-cell lung carcinoma block the neural calcium channels by cross-reaction. ${ }^{[26,27]}$

\section{Palmar fasciitis-polyarthritis syndrome}

Palmar fasciitis-polyarthritis syndrome is mainly related to ovarian carcinoma. However, it may also be associated with endometrial, gastric, and prostate cancers along with leukemia and Hodgkin's disease. The clinical manifestation consists of a thickening of the palmar fascia and symmetrical arthritis which commonly affects the knees, ankles, elbows, and wrists. In severe cases, clinical presentation resembles Dupuytren's contracture. The arthritis is resistant to treatment with corticosteroids and NSAIDs. A cure can be achieved by treatment of the primary tumor. The prognosis is poor if palmar fasciitis-polyarthritis syndrome is associated with metastatic diseases. ${ }^{[28,29]}$

\section{Panniculitis-polyarthritis syndrome}

This syndrome is characterized by inflammation of the subcutaneous adipose tissue and usually is associated with pancreatic malignancies. Arthropathy, subcutaneous sensitive nodules, synovitis, polyserositis, and bone lesions can be observed. The skin lesions appear as tender, red subcutaneous nodules. The possibility of pancreatic cancer should be considered in older patients who present with tender subcutaneous nodules and unexplained arthritis. ${ }^{[10,30]}$

\section{Paraneoplastic eosinophilic fasciitis}

Paraneoplastic eosinofilic fasiitis is an uncommon connective tissue disease characterized by diffuse fasiitis, eosinophilia, unexplained symmetrical pain, and woody induration of the skin at the hands and/ or feet. The disease usually is observed in patients with lymphoproliferative diseases. The skin of the affected extremity is thick and tight. Contractures may develop due to skin sclerosis. The absence of Raynoud's syndrome and unresponsiveness to corticosteroid treatment distinguishes eosinofilic fasiitis from scleroderma. ${ }^{[31,32]}$ 


\section{UNCLASSIFIED SYNDROMES}

\section{Paraneoplastic reflex sympathetic dystrophy (RSD)}

Paraneoplastic RSD is associated with metastatic tumors of the lungs, colon, ovaries, and prostate as well as chronic myeloid leukemia. Typical RSD signs like diffuse burning pain, allodynia, swelling, and decreased extremity function are encountered. ${ }^{[33,34]}$ Symptoms may precede the diagnosis of the underlying malignancy. The pathogenesis is unknown.

\section{Paraneoplastic lupus-like syndromes}

Lupus-like syndromes may be predictive signs for breast and ovarian cancers along with hairy cell leukemia. Clinical manifestation may consist of polyserositis, pneumonitis, Raynaud's syndrome with digital necrosis, non-erosive inflammatory arthritis, and glomerulonephritis. Leucopenia and ANA (antinuclear antibody) positivity can be seen, but ANA positivity without rheumatic symptoms is not predictive of occult malignancy. ${ }^{[2,3,6]}$

\section{Recurrent polychondritis}

Recurrent polychondritis is observed in 30\% of patients with chronic inflammatory diseases and may occasionally be a paraneoplastic syndrome. It is characterized by inflammatory attacks of cartilage tissues at the nose, ears, trachea-bronchial, and joints. Associations with myelodysplastic syndromes and non-Hodgkin's lymphoma have been reported. ${ }^{[35,36]}$

\section{Multicentric reticulohistiocytosis}

Multicentric reticulohistiocytosis is a rare systemic disease presenting with subcutaneous nodular lesions and symmetrical, erosive polyarthritis. Multicentric reticulohistiocytosis is associated with malignancy in about $28 \%$ of reported cases. Histiocytic giant cells are observed in the histological examination of the skin. The arthritis generally involves the proximal and distal phalangeal joints of the hands. This feature helps to differentiate it from RA. The arthritis is selflimiting; however, disability may develop as a result of deformities. Symptoms can be improved when the underlying malignancy is treated. ${ }^{[37,38]}$

\section{Oncogenic osteomalacia}

Oncogenic osteomalacia is associated with benign tumors which originate in the mesenchymal cells. There is hypophosphatemia, hyperphosphaturia, and decreased concentrations of 1.25 dihydroxyvitamin D3 concentrations in the plasma. Diffuse bone pain, spontaneous fractures, and weakness in the proximal muscles can be observed. The possibility of an underlying tumor should be considered in adult osteomalacia of unknown etiology. In the majority of cases, tumor excision is adequate for treatment. If total resection of the tumor is not possible, then phosphate and active vitamin D supplements should be given. ${ }^{[9,39,40]}$

In conclusion, paraneoplastic $\mathrm{RDs}$ refers to symptoms caused by a malignancy but which have no direct relationship to the tumor mass or its metastasis. Certain rheumatic symptoms may be predictive signs of an undiagnosed malignancy. Furthermore, diagnosis of paraneoplastic rheumatic disease can provide early diagnosis of underlying malignancies.

\section{Acknowledgment}

We would like to thank Elif Aydın, M.D. for her contribution to the reviews.

\section{Declaration of conflicting interests}

The authors declared no conflicts of interest with respect to the authorship and/or publication of this article.

\section{Funding}

The authors received no financial support for the research and/or authorship of this article.

\section{REFERENCES}

1. Nathanson L, Hall TC. Introduction: paraneoplastic syndromes. Semin Oncol 1997;24:265-8.

2. Racanelli V, Prete M, Minoia C, Favoino E, Perosa F. Rheumatic disorders as paraneoplastic syndromes. Autoimmun Rev 2008;7:352-8.

3. Szekanecz Z, Szekanecz E, Bakó G, Shoenfeld Y. Malignancies in autoimmune rheumatic diseases - a minireview. Gerontology 2011;57:3-10.

4. Stertz G. Polymyositis. Berl Klin Wochenshr 1916;53:489.

5. Mok CC, Kwan YK. Rheumatoid-like polyarthritis as a presenting feature of metastatic carcinoma: a case presentation and review of the literature. Clin Rheumatol 2003;22:353-4.

6. András C, Csiki Z, Ponyi A, Illés A, Dankó K. Paraneoplastic rheumatic syndromes. Rheumatol Int 2006;26:376-82.

7. Farhey Y, Luggen M. Seropositive, symmetric polyarthritis in a patient with poorly differentiated lung carcinoma: carcinomatous polyarthritis, hypertrophic osteoarthropathy, or rheumatoid arthritis? Arthritis Care Res 1998;11:146-9.

8. Fam AG. Paraneoplastic rheumatic syndromes. Baillieres Best Pract Res Clin Rheumatol 2000;14:515-33. 
9. SchumacherHRJr.Articularmanifestationsofhypertrophic pulmonary osteoarthropathy in bronchogenic carcinoma. Arthritis Rheum 1976;19:629-36.

10. Poelman SM, Nguyen K. Pancreatic panniculitis associated with acinar cell pancreatic carcinoma. J Cutan Med Surg 2008;12:38-42.

11. Segal AM, Mackenzie AH.Hypertrophicosteoarthropathy: a 10-year retrospective analysis. Semin Arthritis Rheum 1982;12:220-32.

12. Olán F, Portela M, Navarro C, Gaxiola M, Silveira LH, Ruiz V, et al. Circulating vascular endothelial growth factor concentrations in a case of pulmonary hypertrophic osteoarthropathy. Correlation with disease activity. J Rheumatol 2004;31:614-6.

13. Katz GA, Peter JB, Pearson CM, Adams WS. The shoulderpad sign-a diagnostic feature of amyloid arthropathy. $\mathrm{N}$ Engl J Med 1973;288:354-5.

14. Fain O, Hamidou M, Cacoub P, Godeau B, Wechsler B, Pariès J, et al. Vasculitides associated with malignancies: analysis of sixty patients. Arthritis Rheum 2007;57:1473-80.

15. Greer JM, Longley S, Edwards NL, Elfenbein GJ, Panush RS. Vasculitis associated with malignancy. Experience with 13 patients and literature review. Medicine (Baltimore) 1988;67:220-30.

16. García-Porrúa C, González-Gay MA. Cutaneous vasculitis as a paraneoplastic syndrome in adults. Arthritis Rheum 1998;41:1133-5.

17. Kurzrock R, Cohen PR. Erythromelalgia and myeloproliferative disorders. Arch Intern Med 1989; 149:105-9.

18. Ljubojević S, Lipozencić J, Pustisek N. Erythromelalgia. Acta Dermatovenerol Croat 2004;12:99-105.

19. András C, Ponyi A, Constantin T, Csiki Z, Szekanecz E, Szodoray P, et al. Dermatomyositis and polymyositis associated with malignancy: a 21-year retrospective study. J Rheumatol 2008;35:438-44.

20. Hill CL, Zhang Y, Sigurgeirsson B, Pukkala E, Mellemkjaer L, Airio A, et al. Frequency of specific cancer types in dermatomyositis and polymyositis: a population-based study. Lancet 2001;357:96-100.

21. Kanaji N, Fujita J, Bandoh S, Fukumoto T, Ishikawa M, Haba R, et al. Small cell lung cancer associated with systemic sclerosis. Intern Med 2005;44:315-8.

22. Bernatsky S, Ramsey-Goldman R, Clarke A. Malignancy and autoimmunity. Curr Opin Rheumatol 2006;18:129-34.

23. Launay D, Le Berre R, Hatron PY, Peyrat JP, Hachulla E, Devulder B, et al. Association between systemic sclerosis and breast cancer: eight new cases and review of the literature. Clin Rheumatol 2004;23:516-22.

24. Glinkov S, Krasnaliev I, Atanassova M, Arnaudov P, Kirov K, Glinkova V. Hepatocellular carcinoma associated with paraneoplastic erythema nodosum and polyarthritis. J
Hepatol 2003;39:656-7.

25. Thomson GT, Keystone EC, Sturgeon JF, Fornasier V. Erythema nodosum and non-Hodgkin's lymphoma. J Rheumatol 1990;17:383-5.

26. Motomura M, Johnston I, Lang B, Vincent A, NewsomDavis J. An improved diagnostic assay for Lambert-Eaton myasthenic syndrome. J Neurol Neurosurg Psychiatry 1995;58:85-7.

27. McEvoy KM. Diagnosis and treatment of Lambert-Eaton myasthenic syndrome. Neurol Clin 1994;12:387-99.

28. Martorell EA, Murray PM, Peterson JJ, Menke DM, Calamia KT. Palmar fasciitis and arthritis syndrome associated with metastatic ovarian carcinoma: a report of four cases. J Hand Surg Am 2004;29:654-60.

29. Santra G. Paraneoplastic palmar fasciitis and polyarthritis syndrome. J Assoc Physicians India 2009;57:79-81.

30. Sagi L, Amichai B, Barzilai A, Weitzen R, Trau H. Pancreatic panniculitis and carcinoma of the pancreas. Clin Exp Dermatol 2009;34:e205-7.

31. Jacob SE, Lodha R, Cohen JJ, Romanelli P, Kirsner RS. Paraneoplastic eosinophilic fasciitis: a case report. Rheumatol Int 2003;23:262-4.

32. Philpott H, Hissaria P, Warren L, Singhal N, Brown M, Proudman S, et al. Eosinophilic fasciitis as a paraneoplastic phenomenon associated with metastatic colorectal carcinoma. Australas J Dermatol 2008;49:27-9.

33. Chefchaouni MC, Francon C, Thiounn N, Gerbaud PF, Sayag Boukris V, Flam T, et al. Severe algoneurodystrophy of the right foot associated with prostatic cancer. J Urol (Paris) 1996;102:243-5. [Abstract]

34. Ameratunga R, Daly M, Caughey DE. Metastatic malignancy associated with reflex sympathetic dystrophy. J Rheumatol 1989;16:406-7.

35. Yanagi T, Matsumura T, Kamekura R, Sasaki N, Hashino S. Relapsing polychondritis and malignant lymphoma: is polychondritis paraneoplastic? Arch Dermatol 2007; 143:89-90.

36. Schwarzer AC, Schrieber L. Rheumatic manifestations of neoplasia. Curr Opin Rheumatol 1991;3:145-54.

37. Nunnink JC, Krusinski PA, Yates JW. Multicentric reticulohistiocytosis and cancer: a case report and review of the literature. Med Pediatr Oncol 1985;13:273-9.

38. Lambert CM, Nuki G. Multicentric reticulohistiocytosis with arthritis and cardiac infiltration: regression following treatment for underlying malignancy. Ann Rheum Dis 1992;51:815-7.

39. Ryan EA, Reiss E. Oncogenous osteomalacia. Review of the world literature of 42 cases and report of two new cases. Am J Med 1984;77:501-12.

40. Schapira D, Ben Izhak O, Nachtigal A, Burstein A, Shalom $\mathrm{RB}$, Shagrawi I, et al. Tumor-induced osteomalacia. Semin Arthritis Rheum 1995;25:35-46. 